\title{
An unusual case of coronary mimicry
}

\author{
Renske Barnhard, ${ }_{1}^{1}$ James Collins, ${ }^{2}$ Froukje Menkveld, ${ }^{1}$ Ewoud ter Avest ${ }^{1}$
}

${ }^{1}$ Department of Emergency Medicine, Medical Centre Leeuwarden, Leeuwarden, The Netherlands

${ }^{2}$ Department of Radiology, Medical Centre Leeuwarden, Leeuwarden, The Netherlands

\section{Correspondence to} Dr Ewoud ter Avest, teravestewoud@hotmail.com

Accepted 6 November 2014
CrossMark

To cite: Barnhard $\mathrm{R}$, Collins J, Menkveld F, et al. BMJ Case Rep Published online: [please include Day Month Yearl doi:10.1136/ bcr-2014-207244

\section{DESCRIPTION}

A 64-year-old man with no significant medical history was referred to the emergency department (ED) due to acute chest pain, suggestive of an acute coronary syndrome. Acetylsalicylic acid $500 \mathrm{mg}$ and glyceryl trinitrate spray had been administered in the ambulance, and when the patient arrived in the ED the chest pain had subsided significantly. At presentation, he was markedly hypertensive (240/ $110 \mathrm{~mm} \mathrm{Hg}$ ). A first ECG (figure 1A) demonstrated left ventricular hypertrophy, but was otherwise unremarkable. However, since troponin $\mathrm{T}$ levels were slightly elevated (32 ng/L, upper reference limit $14 \mathrm{ng} / \mathrm{L}$ ), intravenous nitroglycerine was started and 5000IE of heparin was administered.

Twenty-eight minutes later his condition deteriorated: the chest pain increased and he developed significant abdominal pain and diaphoresis. A second ECG (figure 1B) showed an episode of junctional rhythm $(51 \mathrm{bpm})$, whereas CT scan demonstrated an active abdominal bleeding originating from the right adrenal region extending cranially to the diaphragm (figure $2 \mathrm{~A}, \mathrm{~B}$ ).

Conservative treatment (thrombocyte transfusion and blood pressure control) was initiated in the intensive care unit, where he made a full recovery. During follow-up, metanephrine, normethanephrine and 3-methoxytyramine levels were not elevated, and a fluorodexyglucose (FDG) positron-emission tomography CT scan did not demonstrate an increased FDG uptake in the renal/adrenal region; the bleeding was presumed to be related to severe essential hypertension.

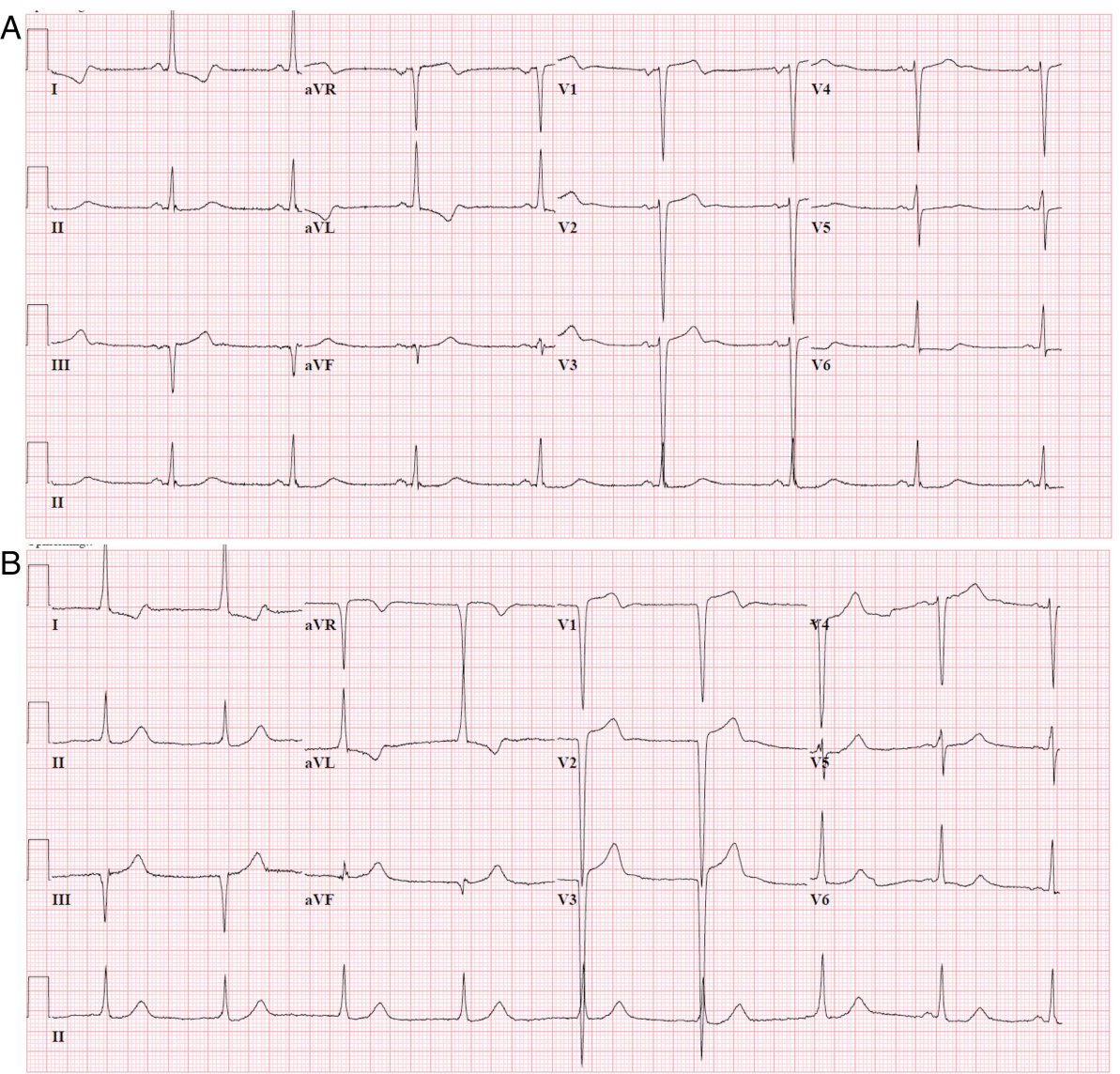

Figure 1 (A) ECG demonstrating sinus rhythm with left ventricular hypertrophy with negative T waves in lateral leads. (B) ECG demonstrating junctional rhythm (with sinus rhythm in last two beats). 


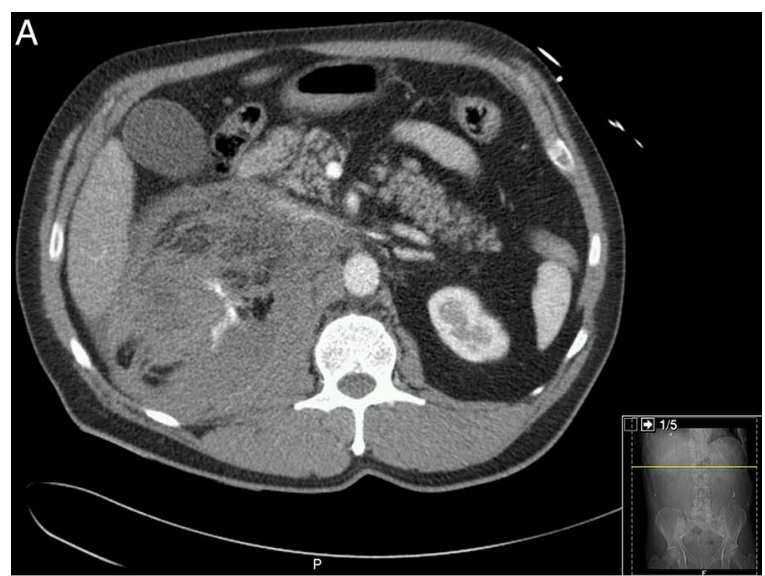

\section{Learning points}

- Intra-abdominal bleeding can present similarly to an acute coronary syndrome (ACS), and should be considered in patients presenting with symptoms suggestive of an ACS before treatment is initiated.

- ECG changes due to extra cardiac disease (known as coronary mimicry), can be present in a variety of conditions. ${ }^{1}$ Our case is the first to describe ECG changes in relation to intra-abdominal bleeding.

- The exact mechanism of the reversible ECG changes seen in cases of intra-abdominal bleeding remains uncertain. A vagally mediated reflex to pain has been postulated for other abdominal causes of ECG changes. In addition, adrenal gland hormone release resulting from adrenal compression might play a role. Finally, hypovolemic shock due to bleeding can lead to ischaemia.

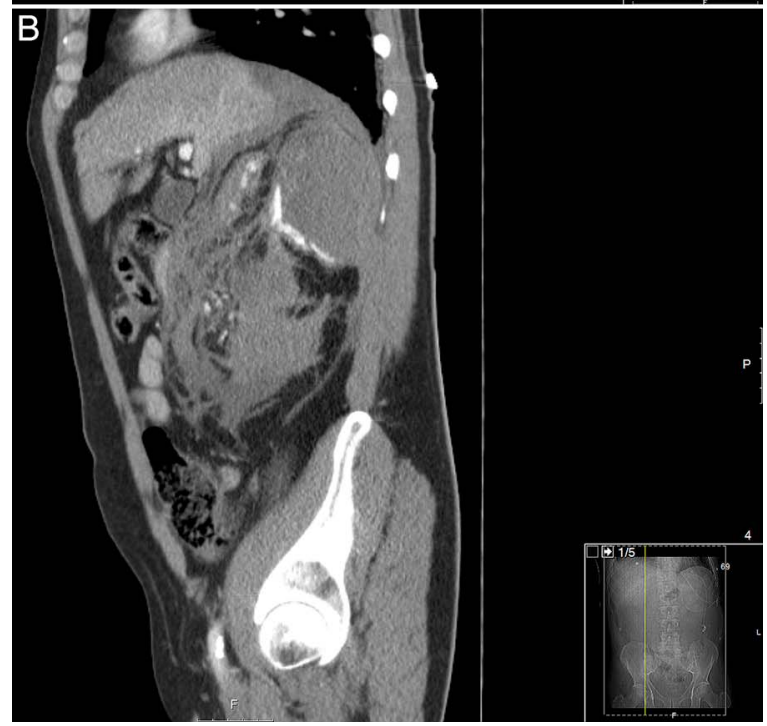

Contributors $\mathrm{FM}$ and $\mathrm{RB}$ were involved in direct patient care. JC reviewed the CT scan. RB and EtA drafted the manuscript.

Competing interests None.

Patient consent Obtained.

Provenance and peer review Not commissioned; externally peer reviewed.

\section{REFERENCE}

1 Pollack ML. ECG manifestations of selected extracardiac diseases. Emerg Med Clin North Am 2006;24:133-43.

Figure 2 (A and B) Large haematoma originating from the right adrenal region with contrast density centrally, indicative of active bleeding.

Copyright 2014 BMJ Publishing Group. All rights reserved. For permission to reuse any of this content visit http://group.bmj.com/group/rights-licensing/permissions.

BMJ Case Report Fellows may re-use this article for personal use and teaching without any further permission.

Become a Fellow of BMJ Case Reports today and you can:

- Submit as many cases as you like

- Enjoy fast sympathetic peer review and rapid publication of accepted articles

- Access all the published articles

- Re-use any of the published material for personal use and teaching without further permission

For information on Institutional Fellowships contact consortiasales@bmjgroup.com

Visit casereports.bmj.com for more articles like this and to become a Fellow 